\title{
De la conciencia a la visión: Job y la contemplación según Girolamo Savonarola*
}

\author{
Ignacio Uribe $M$. \\ INSTITUTO DE FILOSOFÍA \\ PONTIFICIA UNIVERSIDAD CATÓLICA DE VALPARAÍSO
}

I.

La historia de Job es uno de los más ilustrativos actos de fe que nos ofrece el Antiguo Testamento. El protagonista era un patriarca nómade, de gran riqueza y rectitud al que un día Dios decide quitarle todas sus posesiones y sus diez hijos. Le sobreviene una dolorosa enfermedad y en su perplejidad y sufrimiento interpela a la divinidad esperando encontrarse con Él cara a cara para obtener una explicación de cómo un hombre inocente se había hecho merecedor de tales circunstancias. El Creador le habla haciéndolo arrepentirse por haber dudado de su sabiduría, y por su rectificación queda rehabilitado de los males que le aquejaban, siéndole devuelta su prosperidad.

La figura veterotestamentaria de Job fue vinculada a tres particularidades durante la Edad Media. A partir de Job 19, 26 - YYo sé que mi defensor vive, y que él será mi abogado aquí en la tierra. Y aunque la piel se me caiga a pedazos, yo, en persona, veré a Dios»- le fue reconocido el anuncio del misterio de la resurrección. Este aspecto, que se forjó en los inicios del cristianismo ${ }^{1}$, fue enriquecido con una perspectiva histórica y moral que asimiló su persona a la de un hombre santo y paciente. Una tercera característica la encontramos a nivel alegórico pues sus dolores

Esta investigación fue financiada por el Istituto Italiano di Scienze Umane, la Università degli Studi di Firenze y la Pontificia Universidad Católica de Valparaíso.

1 M. Perraymond, La figura di Giobbe nella cultura paleocristiana. Tra esegesi patristica e manifestazioni iconografiche (Ciudad del Vaticano 2002). 
y padecimientos lo convirtieron en una prefiguración de Cristo ${ }^{2}$. Junto a estos tres significados que los estudios han destacado ${ }^{3}$, hay un cuarto que ha sido dejado de lado: Job también fue considerado un ejemplo de la conciencia o discernimiento.

Hacia finales del siglo XV, la imagen convencional de Job permanecía tan vigente como en los primeros siglos del cristianismo ${ }^{4}$. Sin embargo, en su prédica del 14 de marzo de 1495, el monje dominico Girolamo Savonarola explicó cómo Job percibió los premios del Paraíso refiriéndose al rol de la conciencia:

«Siente con el oído y con el intelecto ciertas imaginaciones de la Trinidad, de la Virgen, de la Patria Celeste, y le dan una dulzura y una suavidad en el alma que prácticamente no se puede expresar [...] y considerando esta iluminación y esta luz divina, se vuelca a sí mismo, y considerando sus tenebrosos pecados se horroriza de ellos y parece estar repleto de oscuridad respecto a esa luz. Y, este hombre que lleva en sí un fruto o una flor, ve que todo el mundo está lleno de vanidad y que toda cosa buena es dejada de lado [...]. Et vocem quasi aurae lenis audivi: y sentí una suavidad como de una brisa dulce y suave. Y dice: Stetit quidam coram me et non agnoscebam vultum eius. Es decir, "Yo vi

2 «Job, qui dolens, vel magnus interpretatur, figuram Christi portavit», Jerónimo, Commentarii in librum Job, en J. P. Migne (ed.), Patrologiae cursus completus, series latina, 221 vols. (París 1844-1864), XXIII, col. 619 (sobre la atribución de los Commentarii a Felipe, su discípulo, ver M. P. Ciccarese, «Una esegesi 'doble face’. Introduzione all'Expositio in Job del presbitero Felipe», en C. Moreschini, G. Menestrina (eds.), Motivi letterari ed esegetici in Girolamo (Brescia 1997), $247-$ 268. De ahora en adelante P. L. Jerónimo, Liber de nominibus hebraicis, P. L., XXIII, col. 839; Zeno de Verona, Tractatus, P. L., XI, Tract. I, 15, cols. 441-442.

3 L. Bessermann, The Legend of Job in the Middle Ages (Cambridge (Mass.)-Londres 1979); F. Hartt, "Carpaccio's Meditation on the Passion", The Art Bulletin, XXII (1940), 25-35; G. Von Der Osten, «Job and Christ: The Development of a Devotional Image», Journal of the Warburg and Courtauld Institutes XVI, 1/2 (1953), 153-158.

4 El difundidísimo Speculum humanae salvationis da cuenta de ello. Allí leemos: «Haec etiam flagellatio, duobus modis in Christo perpetrata, / Olim fuit in flagellatione beati Job praefigurata». J. Lutz, P. Pedrizet, Speculum humanae salvationis. Texte critique, traduction inédite de Jean Mielot. Les sources et l'influence iconographique principalment sur l'art alsacien du XIV siècle, I. (Leipzig 1907-1909), I, cap. XX. La bibliografía sobre el Speculum es vasta, por lo que mencionaremos solo dos importantes textos además del recién nombrado: P. Pedrizet, Étude sur le Speculum Humanae Salvationis (Paris 1908); A. Wilson, J. Lancaster Wilson, A Medieval Mirror. Speculum Humanae Salvationis 1324-1500 (Los Ángeles-Londres 1984). 
De la conciencia a la visión: Job y la contemplación según Girolamo Savonarola $\mid 425$

ante mí una imagen que no conocía”, el rostro y la cara de ella (y quiere decir una aparición divina) no conocía, porque Dios no se puede conocer y si lo conociese no habría sido Dios» ${ }^{5}$.

No debiese extrañarnos el juego que estableció Savonarola entre Job y la contemplación ya que, como mencionado al inicio, el patriarca fue interpelado por Dios en dos oportunidades. Finalizada la segunda, al comenzar el último capítulo del Libro, Job dice: «Yo te conocía solo de oídas, pero ahora te han visto mis ojos» $(42,5)$. Pareciera ser, entonces, que el vínculo establecido por el dominico no solo es pertinente, sino que basta una lectura del texto bíblico para prescindir de un estudio que motivase rastrear las huellas de una tradición. Y aunque en este pasaje Job no se presenta tanto como paradigma del discernimiento cuanto de la contemplación, solo en el develamiento de dicha tradición el comentario savonaroliano refleja la profundidad de su análisis.

El propósito de esta investigación es constatar la existencia de fuentes que presentan un vínculo entre Job y el discernimiento para luego ver de qué forma el fraile dominico las consideró mostrando a Job como ejemplo de la contemplación.

II.

La exégesis que Gregorio Magno hizo de Job 42, 5 apuntó a una distinción entre la visión corporal y la visión espiritual:

"Yo te conocía solo de oídas, pero ahora te han visto mis ojos. Con estas palabras indica claramente que así como el ver es por mucho superior al oír, asimismo el progreso que ha alcanzado luego de los padecimientos

5 "Cioè, sente coll'orecchio spirituale e coll'intelletto certe immaginazioni della Trinità, della Vergine, della patria celeste, e songli a costui una dolcezza e una suavità nell'anima sua che quasi esprimere non si può. E perchè e' dice qui il testo: Inhorruerunt pili? Vuol dire considerando questo lume e questa luce che Dio gli dà, si volta poi a se medesimo, e considerando e' suoi peccati tenebrosi, viene in orrore di quelli, e pargli essere pieno di tenbre rispetto a questa luce. E perchè e' vede, questo uomo che fa qualche frutto o qualche fiore, che tutto il mondo è pieno di vanita e che ogni cosa buona è declinata [...]. Et vocem quasi aurae lenis audivi: e sentì una suavità come d'un vento dolce a suave. E più dice: Stetit quidam coram me et non agnoscebam vultum eius. Cioè, 'Io viddi dinanzi a me una immagine ch'io non conoscevo': il volto e la faccia di quella (e vuol dire una apparizione divina) e non la conosceva, perchè Dio non si può conoscere e se lo conoscesse non sarebbe stato Dio». G. Savonarola, Prediche sopra Giobbe, I. (Roma 1957), 220-221. 
dista de la situación anterior. Y de la misma manera que el ojo interior había visto la luz de la verdad, considerando las tinieblas de su humanidad, la veía ahora aún mejor» ${ }^{6}$.

El último capítulo que Savonarola tomó y comentó en sus sermones sobre el Libro de Job, fue el décimo segundo. A pesar que la cita del monje corresponde a Job 4, 16, de la comparación con el texto de Gregorio Magno podemos inferir que el versículo referido ha sido puesto en directa relación con el capítulo y versículo analizado por el comentarista. Los vínculos entre ambos vienen dados, en primer lugar, por la mención a los sentidos de la audición y la vista, y luego por la referencia al conocimiento de sí mismo. Pero junto con ello quedan en evidencia importantes diferencias. No solo resulta manifiesta la jerarquía que Gregorio Magno establece entre oír y ver ausente en el ferrarés, también la mención a la luz pareció tener que ser precisada por este último en su explicación del camino hacia la contemplación. Es por ello que el dominico menciona a la imaginación. Pero su presencia queda asimismo supeditada a una capacidad implícita de configurar determinadas imágenes. Savonarola es clarísimo en el tipo de configuraciones a las que se debe dar lugar, a pesar que ellas sean prácticamente inexpresables. Tal dificultad de proyección imaginativa, en cambio, queda manifestada en la compleja metáfora visual en que convierte la cita bíblica hablando de una brisa dulce. Aquí radica uno de los puntos más ilustrativos de la descripción del dominico, pues el uso de la sinestesia resulta ser una de las claves para comprender las imágenes que se presentan en la contemplación, como queda explicitado al final del pasaje. Dicho obstáculo respondía, al mismo tiempo, a las características que la teología dominica había atribuido a la percepción beatífica. En ella se especulaba acerca de los cambios que experimentarían cada uno de los sentidos en el Cielo; así, por ejemplo, la vista y el oído podrían ver y sentir sin importar la distancia a la que se encontrasen de los objetos ${ }^{7}$. Si los sentidos lograsen

"Auditu aure audivi te, nunc autem oculus meum videt te. His nimirum verbis aperte indicat quia quanto visus superior est auditu, tanto differt ab eo quod prius exstitit, et hoc quod postmodum per flagella profecit. Et quia interno oculo veritatis lumen magis conspexerat, humanitatis suae tenebras diiudicans plus videbat». Gregorio Magno, Moralia in Job, IV y IV(Roma 1992-1994), XXXV[42, 5].

7 Esta fusión de los sentidos es precisamente una característica de la visión espiritual, en donde la perfectibilidad de la percepción alcanza su máximo grado en la superación de cualquier limitación que pudiera haber existido en la percepción terrenal. Los 
iguales características, en la simultaneidad de la percepción llegarían a adquirir similares facultades que los vincularían.

Aunque la cercanía entre Savonarola y Gregorio Magno está dada por el vínculo que el primero establece entre Job 4, 16 y Job 42, 5, la complejidad del pasaje del monje dista en otros puntos del comentario del exégeta. Un nuevo indicio en ese sentido lo da el Benjamin Minor de Ricardo de San Víctor.

III.

En el tratado Sobre la preparación del alma a la contemplación o Benjamin Minor, Ricardo de San Víctor explica el proceso que debiese seguir todo aquel que desee alcanzar la contemplación. Las trece etapas que culminan en la contemplación, están divididas en cuatro grupos, los que a su vez pueden subdividirse en dos. La primera pareja está conformada por el sentimiento y la sensibilidad, y la segunda por la razón, que va acompañada de la imaginación. El sentimiento y la razón se ubican en los extremos del proceso. Son, podríamos decir, el punto de inicio y la meta del camino que sigue el alma humana en su ascenso hacia los misterios divinos. No es el fin del presente estudio dar una descripción detallada de las etapas propuestas por Ricardo, nuestra intención es mostrar cuáles son los aportes de su tratado que fueron recogidos en el pasaje de Savonarola que nos interesa. En este sentido, es importante destacar cómo el dominico se inscribe en una tradición en la que los aportes del Benjamin Minor parecen fundamentales. La contemplación se ubica en el ámbito de lo inteligible junto al discernimiento, ambos son consecuencia de la consideración de los males y bienes futuros que generan una alegría interior cuyo correlato instantáneo es el odio de los vicios y la vergüenza. Estos sentimientos se unen, entonces, en la razón por medio de la imaginación dando lugar a un progreso equivalente al que leemos en el sermón de Savonarola. Dirá Ricardo:

tratados sobre esta materia desarrollados en el ambiente dominico a comienzos del siglo XV, analizan con profundidad y delicadeza estas ideas. Ver, B. LAPACCI DE'Rimbertinus, De deliciis sensibilibus paradisi (Venecia 1498). Acerca del origen de este tratado ver, T. Käppeli O.P., «Bartolomeo Lapacci de’Rimbertini (14021466). Vescovo, Legato Pontificio, Scrittore», Archivum Fratrum Praedicatorum, IX (1939), 86-127. 
"[...] el verdadero discernimiento, en el momento de la tentación, entre las fantasías de la sugestión, desde sus cualidades descubre los peligros futuros y revela a quien sea, a la confesión de sus pensamientos, las insidias de los males inminentes y lo prepara para los futuros peligros» ${ }^{8}$.

Quienquiera conocer el misterio divino debe seguir la máxima délfica del conocimiento de sí mismo evitando corromper el espíritu, tal como lo hizo Job ${ }^{9}$, dirá pocas líneas más adelante ${ }^{10}$. Job irrumpe aquí con decisión como un ejemplo de discernimiento dentro de la sucesión espiritual demarcada por el teólogo y que Savonarola seguirá de cerca. Pero esta adscripción al Benjamin Minor muestra una faceta particular dentro de la tradición dominica cuando leemos el comentario a las Sentencias de Pedro Lombardo escrito por Tomás de Aquino. Este, centrándose en Job 42, 5, dice:

«La palabra de Job puede ser entendida respecto de la visión imaginaria o de la intelectual. Si es entendida como imaginaria, queda designado el progreso de Job en el grado de la profecía: dado que primero le había sido entregada la revelación a través del oído; después, en cambio, mediante su visión. Si es entendida como visión intelectual, entonces se muestra un progreso que va desde el conocimiento por la fe a la inteligibilidad de las realidades divinas, la que en esta vida está presente en los santos a través de la contemplación. Esta debe ser ciertamente designada como visión, dado que viendo conocemos ciertas cosas recibidas de las cosas mismas, así los santos en la contemplación reciben la luz de Dios mismo» ${ }^{11}$.

8 «[... vera discretio in ipso tentationis articulo, inter ipsa suggestionum phantasmata ex eorum qualitate futura pericula deprehendet, et aliis quibuslibet ad cogitationum suarum confessionem imminentium malorum insidias detegit, et de futuris periculis cautos reddit». Ricardo de SAN Víctor, Beniamino minore, P. L. 196, col. 49.

9 Ricardo de San Víctor, Beniamino minore, cols. 51-52.

10 «[...] et nuntius qui beato Job in omni persecutione sua solus remanere potuit, qui ei perpetrata damna statim renuntiare studuit, quia nisi per discretionem, virtutum damna animus nec cognoscit, nec corrigit». Ricardo de SAN Víctor, Beniamino minore, col. 49.

11 «Quod verbum Iob post intelligi de visione imaginaria et intellectuali. Si enim intelligatur de imaginaria, designatur profectus Iob in gradu prophetiae; cum primo non fuerit ei facta revelatio nisi per auditum loquentis, postmodum vero per visionem loquentis. Si autem intelligatur de visione intellectuali, tunc ostenditur profectus eius de cognitione fidei in intellectum divinorum, qualis hic 
De la conciencia a la visión: Job y la contemplación según Girolamo Savonarola | 429

Tomás de Aquino parece obligar al lector a optar por la imaginación o la razón al momento de interpretar, pero la existencia de una tradición dentro de la teología dominica que siguió el camino establecido por Ricardo de San Víctor determina la opción savonaroliana. En esta, la progresión hacia la contemplación necesariamente debe pasar por la creación de imágenes. En este sentido, imaginación e inteligencia aunque pueden responder a facultades distintas del hombre, forman parte de un único camino. La razón es nutrida por la imaginación. Sin ella y su capacidad para componer, descomponer y recomponer imágenes de las cosas corporales recibidas a través de los sentidos, la razón no sería capaz de elevarse a la comprensión de las cosas incorpóreas. Este punto, delicadamente subrayado por los estudiosos ${ }^{12}$, hace de la imaginación una función primordial del alma humana en su conexión directa con la percepción. Pero, "puesto que Dios es invisible e incorpóreo, la imaginación, aunque sea capaz de entregar indicaciones importantes, es incapaz de mostrar aspectos de Él en cuanto tal; la comprensión teológica que entrega la imaginación es intrínsecamente metafórica» ${ }^{13}$. Es, tal vez, esta la dificultad a la que apuntaba Tomás de Aquino en su distinción. La comparación tácita que implica toda metáfora solo podrá acercarse a la contemplación en la medida que la creación de imágenes responda a una conformación cualitativa del alma que sea reflejo de lo divino. Dios en su incorporeidad se manifiesta en lo incorporal de lo humano. Las imágenes así conformadas tienen un correlato naturalmente divino. La conciencia, en este sentido, corresponde al conocimiento del hombre en cuanto creatura divina imaginada.

La tradición que sigue Savonarola ya se había manifestado en otro texto dominico en donde se muestra tanto el sentido retórico como el teológico de la metáfora, el Colloquio Spirituale (ca. 1391) de Simone de

per contemplationem praedictam habetur a sanctis; quae quidem visio dicitur: quia sicut videndo aliqua cogniscimus, ad ipsis rebus accipiendo; ita sancti in contemplatione accipiunt lumen ab ipso Deo, per quod divina altius ceteris contemplantur». Tomás de Aquino, Commento di S. Tommaso alle sentenze di Pietro Lombardo, X. (Boloña 2002), lib. 4, dist. 49, q. 2, art. 7, sol. 1 ad 3.

12 N. Den Bok, Communicating the Most High. The Systematic Study of Person and Trinity in the Theology of Richard of St. Victor (París 1996), 131-32.

13 Idem. 
Cascina ${ }^{14}$. A partir del discurso que desarrolla el fraticello en el diálogo que llevan adelante los cuatro personajes en torno al significado de la misa, es posible determinar la presencia del Benjamin Minor pues sigue las etapas allí propuestas en el camino hacia la contemplación. Ante la afirmación de Simone, otro de los personajes, proponiendo la existencia de tres cielos -que en orden ascendente corresponden a la visión corporal, a la visión imaginaria y a la visión intelectual-, el fraticello responde enfáticamente:

«Tengo una opinión distinta [...] de cómo se eleva el alma a la contemplación [...] viendo la increada Sabiduría a la razón abatida por la carnalidad, maldita por el pecado, ciega por la ignorancia, entregada solo a las cosas externas, con clemencia la coge, con potencia la eleva, con prudencia la educa y llevándola dentro la hace juzgarse a sí misma [...] enseñándole a subir al primer cielo de la humildad.

Luego viene el Espíritu Santo y viendo la voluntad corrompida de venenosos apetitos mortales la visita y alentándola le muestra el esplendor de la razón. Este con suavidad la purifica, con afecto la reanima, la hace misericordiosa [...] y así la amaestra para elevarse a lo alto del espacioso segundo cielo.

Por su perfectísima caridad ilustrada por la razón y llena de humildad [...] el alma se purifica [...] Es por esto que el Padre la rapta y lleva a sí, y como una gloriosa esposa se le une y vincula [...] haciéndola gozar de la contemplación $[\ldots] »^{15}$.

14 Simone da Cascina nació en Pisa en la mitad del siglo XIV. Entró en el Convento de Santa Caterina donde ejerció un rol de primer plano. Fue en tres oportunidades prior del Convento y profesor de teología sacra no solo en el mismo, sino además en Siena, Perugia y Florencia. Véase, Simone da Cascina, Colloquio Spirituale, (Florencia 1982); T. KäpPELI, «La raccolta di discorsi e atti scolastici di Simone da Cascina", Archivum fratrum praedicatorum XII (1942), 185-246.

15 «Sono d'altra opinione [...] come saglia l'anima al terso cielo [...] Vedendo la increata Sapiensia la ragiona abattuta per la carnalità, cattivata per il peccato, cieca per la gnoransia, data sola a cose di fuora [...] tirandola dentro, la fa esser di se stessa giudici [...] l'insegna a salire lo primo cielo della profundissima umiltà».

«Poi viene lo Spirito Santo e, vedendo la volontà corrotta di velenosi appetiti mortiferi, sidegna di viziarla e allenttandola lo sprendore della ragione li mostra. Onde con suavità la purga, con affetto l'accende, falla misericordiosa [...] e così làmmaestra a saglire in su lo spasioso cielo secondo».

«Di perfettisima carità illustrata la ragione e ripiena d'umiltà [...] diventa l'anima sensa macchia [...] Perciò il sommo Padre la rapisce e tira a sé, e per groriosa spoza 
De la conciencia a la visión: Job y la contemplación según Girolamo Savonarola | 431

Simone sigue de cerca a Ricardo destacando con fuerza la capacidad divina de la razón. Si las imágenes son las que median entre el mundo exterior y el mundo interior influenciando el destino del hombre al determinar sus opciones morales, es esencial poder controlarlas y modificarlas ${ }^{16}$. En aquel control, modificación y reelaboración, la razón es capaz de ilustrar el más divinos de los dones, la caridad. Es en este paso donde el alma humana se une con lo divino por medio de la imaginación y contemplación.

Parece evidente que el sermón de Savonarola se inserta dentro de esta línea de pensamiento, pero la presencia de Ricardo de San Víctor en un texto elaborado dentro de la teología dominica, aunque demuestra la importancia de la tradición que hemos rastreado, no es suficiente para establecer la figura de Job como símbolo del discernimiento ni tampoco resolver el problema que hemos dejado planteado líneas más arriba: de qué forma la conformación de imágenes responde a una pureza espiritual que permita alcanzar la contemplación.

IV.

Finalizando la primera parte de su Tractatus de configurationibus qualitatum et motuum, el teólogo y matemático francés Nicolás Oresme desarrolla una interesante teoría acerca de la visión espiritual. El Tractatus está compuesto por noventa y tres capítulos divididos en tres partes. La primera establece los parámetros geométricos de la doctrina figurativa, es decir, los elementos permanentes o durables en el tiempo que se relacionan con la configuración interna de las cualidades. La segunda parte indaga la forma en que la doctrina configurativa puede ser aplicada al movimiento o sucesión de entidades. Finalmente, en la tercera parte Oresme, volviendo al uso de las figuras geométricas, demuestra cómo a partir de ellas podemos confrontar diferentes cualidades y movimientos $^{17}$. De las tres definiciones del concepto de configuratio que aparecen en el Tractatus, aquí nos centraremos en la llamada configuratio espiri-

se l'unisce e congiunge [...] la fa pascere in della contemplassione [...]». Simone Da Cascina, Colloquio spirituale, 28, 12 ss.

16 L. Bolzoni, Le rete delle immagini. Predicazione in volgare dalle origini a Bernardino di Siena (Turín 2002), 56.

17 Para una completa descripción y análisis del tratado de Oresme ver, M. Clagett, Nicole Oresme and the Medieval Geometry of Qualities and Motions. A Treatise on 
tual, cuya característica fundamental es la de intentar unir la doctrina configurativa con una idea estética.

Según Oresme, la diferencia entre el sentido exterior y el sentido interior es que en el primero la visión no siempre retiene el objeto visto, mientras en el segundo ocurre lo contrario al no necesitar la presencia del objeto para representarlo ( tal como la huella permanece en la cera después que el sello ha sido retirado» $\left.{ }^{18}\right)$. De ahí que el intelecto pueda ser figurado correcta o incorrectamente. Como ha sido destacado, este punto permite a Oresme distinguir entre el concepto que nos formamos de las cosas y las cosas en sí mismas ${ }^{19}$. Sin embargo, la impresión de la cosa observada dependerá de la idea de placer que se tenga. Por ejemplo, explica el teólogo, quien se deleite imaginando figuras deformes, será una persona cuya calidad natural está corrompida; lo contrario ocurre respecto de quienes aborrecen la deformación, lo que sería signo de una correcta configuratio qualitatum ${ }^{20}$. La figura se transforma, y junto con ella la visión, en una expresión del espíritu. El problema se refleja con mayor claridad en el capítulo XXXII de la obra de Oresme, en donde quedan establecidos los presupuestos necesarios para alcanzar una visión espiritual uniforme que acerque al hombre a la contemplación. Allí aparece Job al centro de la explicación:

«[...] un alma ocupada en demasiados pensamientos y afectada por muchas pasiones, es áspera y deforme. Por lo tanto, a veces por abstracción o volviéndonos hacia una cosa intentamos borrar este tipo de deformidad y sin embargo no podemos, como la experiencia nos enseña que algunas personas no logran dejar de lado ciertas meditaciones y preocupaciones que con frecuencia se repiten en ellas a pesar que no las deseen. En ocasiones, no obstante, el alma logra abstraerse de di-

the Uniformity and Diformity of Intensities Known as Tractatus de Configurationibus Qualitatum et Motuum (Madison-Milwaukee-Londres 1968), 3-155.

18 «Sicut vestigium amoto sigillo restat in cera». N. ORESME, De configurationibus, cap. 31, en Nicole Oresme and the Medieval Geometry 248-251. Sobre el problema del conocimiento en Oresme ver, Fabio Zanin, Passio corruptivalpassio perfectiva: A Basic Distinction in Oresme's Theory of Knowledge, en "Quia inter doctores et magna dissensio. Les débats de philosophie naturelle à Paris au XIVe siècle», Stefano Caroti et al. (eds.), (Florencia 2004), 135-139.

19 A. Davenport, Measure of a Different Greatness. The Intensive Infinite, 1250-1650 (Leiden-Boston-Köln 1999), 375.

20 N. Oresme, De configurationibus, cap. 30. 
De la conciencia a la visión: Job y la contemplación según Girolamo Savonarola | 433

chas cosas y remueve las deformidades y asperezas. Así puede después decir como Job: "Mis pensamientos han disipado los tormentos de mi corazón” (Job. 17, 11)»"

En consecuencia, es posible proyectar una imagen divina apartando las deformidades o asperezas del pensamiento. Para ello el espíritu debe quedar libre de imágenes sensibles figuradas desde pensamiento terrenales si pretende alcanzar un estado de uniformidad y pureza. Job entra en el misterio divino, según Oresme, precisamente desde un acto de conciencia. Sabe que al desaparecer aquello que lo atormentaba, está preparado para la contemplación.

Una vez explicada la relación entre la uniformidad y la deformidad del espíritu a partir de la visión, Oresme se adentra, en el capítulo sucesivo dedicado a la visión espiritual, en la problemática de la pureza del alma, la que permite al hombre, dice, observar los misterios divinos. La deformidad de los pensamientos impide, explica, acceder al conocimiento de las cosas que se esconden a los ojos corporales. El alma, en su capacidad de controlar las pasiones, accede a una visión pura por medio de la abstracción: su uniformidad está capacitada para recibir aquello que de otra forma no podría ser evidente. Junto con comparar la visión de Dios a un espejo, Oresme afirma que el alma constituye un medio para alcanzar la misma. La visión de lo divino es un acto espiritual que por medio de la uniformidad obtenida por la conciencia, permite adentrarse en un espacio celestial que finalmente hallará la contemplación. Así, Job resulta ante los ojos de Oresme un paradigma del discernimiento en su capacidad para volcarse hacia sí mismo.

El rol atribuido por Oresme a la imagen en la teoría del conocimiento de los misterios divinos, se ajusta con mayor exactitud al pasaje del sermón de Savonarola citado al inicio de este artículo. El sentir ciertas imaginaciones, como declara el dominico, no solo se fundamenta en el progreso hacia la contemplación sino que ellas son el resultado de una

21 «[...] anima enim mutiplicibus cogitationibus occupata et passionibus affectata facta est quasi aspera et defformis. Quandoque igitur per abstractionem vel conversionem eius ad unum ipsa nititur huiusmodi difformitatem delere et tamen non potest sicut experimento patet quod aliqui quasdam meditationes et sollicitudines non possunt abicere sed ipsis invitis frequenter occurrunt. Quandoque vero anima potest seipsam a talibus abstrahere et priorem diformitatem seu asperitatem excutere, ut postea dicere possit, "cogitationes mee dissipate sunt, torquentes cor meum"». N. Oresme, De configurationibus, cap. 32. 
434 | Ignacio Uribe M.

forma correcta de imaginar que no puede ser desvinculada del valor moralizante que Savonarola imprime a sus sermones. Desde esta perspectiva, el papel dado a Job en Oresme solo podía derivar en mostrarlo como un símbolo de la contemplación. Dado que la pretensión de Savonarola era la de alejar a quienes lo oían de las vanidades, la incorporación en nuestra hipótesis del texto de Oresme requiere de una justificación puesto que su circulación en Italia no tenía la misma suerte que el resto de las obras comentadas a lo largo de nuestra argumentación.

V.

Hacia 1500 se encontraba en la Biblioteca del Convento de San Marco la copia de una paráfrasis y comentario al Tractatus de configurationibus qualitatum et motuum ${ }^{22}$. La presencia del mismo en el catálogo de la biblioteca, aunque supone una solución a nuestro problema, no basta para ligar el sermón de Savonarola con el contenido exacto de la obra de Oresme. De ahí que sea necesaria una justificación que demuestre no solo su existencia en Florencia sino además esta pudo ser conocida por el dominico.

Las universidades italianas desde 1420 estaban al corriente de las doctrinas de Oresme presentes en el De configuationibus ${ }^{23}$. Dos ejemplos de ello fueron el Tractatus de latitudinibus formarum de Jacobus de Sancto Martino, escrito ca. 1390 y el Questiones super tractatum de latitudinibus formarum de Blasius de Parma ${ }^{24}$. Asimismo, el testamento de Bernardo Torni, profesor del studio florentino a finales del siglo XV, deja entrever que fue poseedor de una gran cantidad de libros que cubrían los más variados intereses, los que iban desde la poesía hasta las más distintas

22 Ms. Florencia, Biblioteca Nazionale Centrale, Conv. Soppr. J.IX.26, fols. 13r-35r. El manuscrito no es mencionado en B. L. Ullman y P. A. Stadter, The Public Library of Renaissance Florence. Niccolò Niccoli, Cosimo de' Medici and the Library of San Marco (Padua 1972). Esta ausencia fue notada por primera vez en el estudio de A. A. BJornio, Die mathematischen S. Marcohandschriften in Florenz (Pisa 1976), 5 y 23-24.

23 P. Dunem, Études sur Leonard de Vinci. Le précurseurs parisiens de Galileé, III (París 1913), 485.

24 Sobre el De latitudinibus ver M. Clagett, Nicole Oresme and the Medieval Geometry, 85 ss. Sobre Blasius y Oresme ver P. Dunem, Etudes sur Leonard de Vinci, III, 399400 y $483-484$. 
De la conciencia a la visión: Job y la contemplación según Girolamo Savonarola | 435

ciencias $^{25}$. Si bien no conocemos una lista con los títulos precisos, la reconstrucción de sus intereses pude obtenerse de sus estudios. Es así como se ha llegado a la conclusión que este era un destacado conocedor de las obras de Swineshead, Heytesbury, Bradwardine, Alberto de Sajonia y Oresme ${ }^{26}$. Si bien no es posible afirmar que el representante del studio florentino fuese uno de los pocos poseedores del De configurationibus en Italia, su contacto con Giovanni Pico della Mirandola -quien ejerció una importante influencia en ese entorno- nos entrega un nuevo indicio.

El estudio sobre las bibliotecas italianas del Quattrocento y la matemática renacentista ha enfatizado el rol que tuvieron los humanistas en los estudios científicos de la época ${ }^{27}$. En ese contexto Pico della Mirandola aparece como un personaje central no solo para comprender su relación con el studio, sino también por la suerte que corrieron sus libros luego de su muerte. Una vez ocurrida esta, y antes que su biblioteca fuese vendida al cardenal Grimani de Venecia, los libros de Pico fueron custodiados en el convento dominico de San Marco entre 1494 y 1498. Estos cuatro años, que coinciden temporalmente con el sermón que aquí nos interesa, adquieren una fundamental relevancia si consideramos que entre las posesiones del humanista se encuentra una copia de la obra de Oresme ${ }^{28}$. En el catálogo de su biblioteca aparece nombrado entre sus posesiones un manuscrito con De configurationibus qualitatum

25 A. Verde, Lo studio fiorentino, II (Florencia 1973-1994), 134-135.

26 de Giorgio Valla, las bibliotecas más importantes en textos científicos del período. Véase L. Labowsky, Bessarion's Library and the Biblioteca Marciana. Six Early Inventories (Roma 1979); J. L. HeiberG, «Bestrage zur Geschichte Georg Valla's und seines Bibliothek», Beihefte zum Centralblatt für Bibliothekswesen XVI (1896), 353-481. Asimismo, en la Biblioteca Laurenziana de Florencia subsiste otra copia (Ashburnham 210) de origen parisino, datado 1410; hacia 1473 se encontraba en posesión de un tal Bernardino Cepolle de Verona, como aparece escrito en el mismo manuscrito: "1473. Iste liber est mei Bernardini Cepolle da Verona». Ver C. Paoli, I Codici Ashburnhamiani della Biblioteca Mediceo-Laurenziana (Roma 1891), I, fasc. 3, 51. 
Orem et alia $^{29}$, texto que probablemente haya conseguido durante su estadía en París ${ }^{30}$. Como sea que fuese, queda establecida con claridad la posibilidad que tuvo Savonarola de conocer el texto de Oresme.

VI.

Como ya hemos mostrado, para Savonarola la beatitud de Job le permitía estar en un constante estado de contemplación determinado por la imaginación como forma de aprehensión de realidades divinas. No debe extrañarnos entonces que en su quinta prédica sobre el patriarca veterotestamentario, hable de él como un hombre que se encontraba entre las cosas espirituales con el alma y la mente. Sabemos, a partir de Oresme, que aquello que es imaginado está determinado por una correcta figuración que tiene como fundamento el discernimiento. Así, es preciso notar cómo el "volcarse a sí mismo» de Job es un elemento esencial en la progresión hacia la visión espiritual, exactamente como lo veíamos en Ricardo de San Víctor y en Oresme. Savonarola hace del progreso hacia la contemplación un movimiento circular que parece casi confundir la conciencia con la visión. Este aparente malentendido se resuelve leyendo con atención el inicio del pasaje del sermón que hemos citado: "[Job] siente con el oído y con el intelecto ciertas imaginaciones». Sentir con el oído espiritual es la llave de entrada para poder imaginar, pero dichas imaginaciones han de estar correctamente configuradas. Para Savonarola solo sus sermones podían alejar a las personas de las configuraciones erradas surgidas desde la vanidad. Si lo imaginado es lo visto sin impurezas gracias al mismo Savonarola, entonces este, al devenir el referente para la creación de configuraciones libres de cualquier deformidad, se muestra a sí mismo con las mismas características de Job, como un beato y profeta. El primer caso justifica la posición de Job como ejemplo

29 P. Kibre, The Library of Pico della Mirandola (New York 1936), 209 y 21. Luego de la muerte del cardenal Grimani su biblioteca fue donada al Monasterio de San Antonio de Castello con el propósito de erigir una biblioteca de uso público. En 1687 un incendio destruyó el refectorio, donde se conservaban no solo una serie de valiosas pinturas, sino también «libros griegos y hebreos y otros raros manuscritos». Como afirma Kibre, es probable que estos fuesen los libros de Pico y que por lo tanto las obras mencionadas en el catálogo hayan sido consumidas por el fuego. Véase, E. A. Cicogna, Delle iscrizioni veneziane, I (Venecia 1824-1853), 365.

30 P. O. Kristeller, «The Scholastic Background of Marsilio Ficino», en Studies in Renaissance Thought and Letters, I (Roma 1984), 35-97. 
De la conciencia a la visión: Job y la contemplación según Girolamo Savonarola | 437

de contemplación y lo vincula al segundo en su misión salvadora de la nueva Jerusalén Celeste, Florencia. Así era percibido por sus seguidores, y no hay mejor ejemplo de ello que la inscripción que Fra Bartolomeo puso (ca. 1500) en su retrato del monje: «Esta es una pintura de Fra Girolamo Savonarola, un profeta enviado por Dios» ${ }^{31}$.

31 «Hieronymi Ferrarensis A Deo Missi Prophetae Effigies». Ver D. Weinstein, «Explaining God's Acts to His People: Savonarola's Spiritual Legacy to the Sixteenth Century", en J. W. O'Malley et al. (eds.), Humanity and Divinity in Renaissance and Reformation. Essays in Honor of Charles Trinkaus (Leiden 1993) 205-225. La datación de la obra sigue siendo tema de debate. Sobre este problema ver, G. Damiani, «Ritratto di Girolamo Savonarola», en L'età di Savonarola. Fra" Bartolomeo e la scuola di San Marco, S. Padovani (ed.) (Venecia 1996). 281-283. 
Resumen: La figura veterotestamentaria de Job durante la Edad Media fue identificada fundamentalmente con tres significados: prefiguración de Cristo, resurrección y paciencia. Los estudios han dejado de lado una cuarta posibilidad que lo identificaría con el discernimiento. En este contexto es posible rastrear una tradición de la que el monje dominico Girolamo Savonarola es heredero. A partir de un breve pasaje de uno de sus sermones dedicados al Libro de Job, el presente trabajo busca comprender, por una parte, cuáles fueron los presupuestos teológicos que utilizó en su explicación del ascenso del alma a la contemplación y, por otra, por qué la figura de Job jugó un rol central en ella.

Palabras clave: Job, Girolamo Savonarola, discernimiento, contemplación, configuración.

Abstract: During the Middle Ages, Job had mainly three allegorical meanings, namely: Christ's perfiguration, resurrection and patience. Nevertheless, scholars have not considered a forth one which identifies him with discerniment. This article traces the tradition of this meaning inherited by Girolamo Savonarola. From a fragment of his Sermons on Job, we show, on the one hand, the theological ideas that the friar used in his explanation of the ascent of the soul towards contemplation, and on the other, the importance of Job in this process.

Keywords: Job, Girolamo Savonarola, discerniment, contemplation, configuration. 